\title{
Perbedaan Kemampuan Berpikir Kritis Matematis Siswa antara Model Pembelajaran Problem Posing dan Discovery Learning
}

\author{
Raya Nababan ${ }^{(1)}$ Irvan $^{(2)}$; Zainal Azis ${ }^{(2)}$. \\ Mahasiswa Pascasarjana Universitas Muhammadiyah Sumatera Utara ${ }^{(1)}$; Dosen Pascasarjana \\ Universitas Muhammadiyah Sumatera Utara ${ }^{(2)}$. \\ rayanababan040978@gmail.com irvan@umsu.ac.id zainalazis@umsu.ac.id
}

\begin{abstract}
Abstrak
Penelitian ini dilaksanakan di SMA Negeri 1 Kutalimbaru Tahun Ajaran 2020/2021 untuk mengetahui perbedaan kemampuan berpikir kritis matematis siswa antara model pembelajaran problem posing dan discovery learning. Pengumpulan data penelitian menggunakan teknik observasi untuk melihat pencapaian proses pembelajaran sudah sesuaI atau tidak dengan model pembelajaran dan tes untuk melihat perbedaan kemampuan berpikir kritis matematis serta siswa antara model pembelajaran problem posing dan discovery learning. Hasil penelitian menunjukkan bahwa: 1) pencapaian proses pembelajara problem posing adalah sebesar 4,8 dengan kategori "Sangat Baik" pencapaian proses pembelajaran discovery learning adalah sebesar 4,867 dengan kategori "Sangat Baik". 2) Tidak terdapat perbedaan kemampuan berpikir kritis matematis antara siswa yang memperoleh model problem posing dengan discovery learning. Hal ini terlihat dari hasil uji statistika, dimana nilai probabilitas (sig.) untuk kedua pembelajaran lebih besar dari taraf signifikansi $\alpha=0,05$ yang ditetapkan, sehingga $\mathrm{H}_{0}$ diterima. Namun secara matematis nilai rata-rata kemampuan berpikir kritis matematis siswa berbeda
\end{abstract}

Kata Kunci: Problem Posing; Discovery Learning; Berpikir Kritis

\begin{abstract}
This research was conducted at SMA Negeri 1 Kutalimbaru for the academic year 2020/2021 to determine the differences in students' mathematical critical thinking skills between the problem posing learning model and discovery learning. Data is collected using observation techniquesto see the achievement of the learning process whether or not it is in accordance with the learning model and tests to see the differences in mathematical critical thinking skills and students between the problem posing learning model and discovery learning. The results showed that: 1) the achievement of the learning processproblem posing amounted to 4.8 in the "Very Good" category achievement process Discovery learning is equal to 4.867with the "Very Good" category. 2)There is no difference in mathematical critical thinking skills between students who obtain the problem posing model and discovery learning. This can be seen from the results of the statistical test, where the probability value (sig). For the two lessons is greater than the significance level. $\alpha=0.05$ specified, so that $\mathrm{H} 0$ is accepted. However, mathematically, the average value of students' mathematical critical thinking skills is different
\end{abstract}

Keywords: Problem Posing; Discovery Learning; Critical thinking

\section{PENDAHULUAN}

Salah satu tujuan utama pendidikan adalah menyiapkan manusia dengan kompetensi yang diperlukan bagi kehidupan. Untuk mencapai manusia dengan kompetensi tingkat tinggi maka diperlukan suatu penguasaan konsep yang akan membawa setiap peserta didik untuk dapat mengkomunikasikan setiap konsep-konsep sehingga peserta didik mampu berpikir secara subjek dan konten terhadap suatu masalah. Karena itu sangat dibutuhkan suatu kemampuan berpikir kritis karena berpikir kritis adalah cara berpikir tentang subjek dan konten terhadap suatu masalah apa pun di mana pemikir tersebut dapat meningkatkan kualitas pemikiran peserta didik secara terampil untuk mengambil alih struktur yang melekat dalam pemikiran dan menerapkan standar intelektual padanya (Ugwuozor Felix Okechukwu, 2021). 
Untuk mencapai suatu kemampuan berpikir kritis yang tinggi maka diperlukan komunikasi yang efektif dan kemampuan pemecahan masalah yang dapat membantu warga negara memahami dunia mereka dan berpartisipasi dalam dialog demokratis (Bansal P., 2011). Untuk mempersiapkan warga negara dengan keterampilan berpikir tingkat tinggi harus menjadi prioritas utama dari sistem pendidikan apa pun. Oleh karena itu, merupakan tanggung jawab guru untuk mengembangkan keterampilan berpikir kritis siswanya dan beralih ke metode konstruktivis sehingga siswa dapat mengkonstruksi pengetahuannya dan menerapkannya untuk memecahkan masalah kehidupan nyata.

Pada tujuan mata pelajaran matematika, selain agar siswa memahami konsep matematika tetapi juga agar siswa mampu berkomunikasi, bernalar, memecahkan masalah, berpikir tingkat tinggi, serta dapat menggunakan pengetahuannya dalam kehidupan sehari-hari (Situmorang Adi S., 2019). Pernyataan ini semakin memperkuat bahwa kemampuan berpikir kritis perlu sekali untuk dimiliki oleh setiap peserta didik untuk mencapai tujuan dari pendidikan nasional karena berfikir kritis dapat dihasilkan dari kemampuan untuk membentuk generalisasi yang valid, eksplanasi, prediksi, hipotesis dan perbandingan (Panggabean Ellis, 2015).

Penelitian tentang berpikir kritis sebagaimana diutarakan oleh Olalekan (2017) yang menyatakan bahwa kemampuan berpikir kritis seorang calon guru merupakan faktor yang akan menentukan sejauh mana mereka akan menstimulasi dan mentransfer keterampilan yang sama kepada siswanya di masa depan. Sedangkan pernyataan lain, ada juga yang menyatakan bahwa seorang siswa dengan kemampuan berpikir kritis yang dikembangkan dengan mengembangkan kecakapan hidup akan dapat membantu mereka dalam pemecahan masalah baik dalam kehidupan pribadi maupun profesional setelahnya (Esmaeili, Z., \& Bagheri, M. 2015; Enciso, Enciso, \& del Pilar Vargas Daza, 2017). Sehingga dari pernyataan ahli tersebut disimpulkan bahwa Budaya berpikir kritis yang berkelanjutan menandakan perbedaan yang luar biasa dalam sistem pendidikan, dan karenanya, tingkat perkembangan antara negara maju dan berkembang (Ugwuozor Felix Okechukwu, 2021).

Dari pernyataan tersebut jelas bahwa seorang guru selain memiliki kemampuan berpikir kritis, juga harus mampu merangsang kemampuan berpikir kritis peserta didik mucul saat proses belajar mengajar. Untuk dapat merangsang kemampuan yang dimiliki oleh peserta didik khususnya kemampuan berpikir kritis maka seorang guru harus mampu memilih model pembelajaran yang tepat (Sianipar Linda, 2015; Siahaan Friska, 2015).

Problem posing merupakan istilah dalam bahasa inggris yang berasal dari dua kata yaitu problem yang artinya masalah, soal dan posing dari to pase yang berarti mengajukan, membentuk. menurut Silver (Muhfida, 2011) bahwa problem posing mempunyai tiga pengertian, yaitu: pertama, problem posing adalah perumusan soal sederhana atau perumusan ulang soal yang ada dengan beberapa perubahan agar lebih sederhana dan dapat dipahami dalam rangka memecahkan soal yang rumit (problem posing sebagai salah satu langkah problem solving). Kedua, problem posing adalah 
perumusan soal yang berkaitan dengan syarat-syarat pada soal yang telah dipecahkan dalam rangka mencari alternatif pemecahan lain (sama dengan mengkaji kembali langkah problem solving yang telah dilakukan). Ketiga, problem posing adalah merumuskan atau membuat soal dari situasi yang diberikan.. Problem posing dalam matematika adalah proses merumuskan dan mengungkapkan masalah dalam domain matematika dimana setiap konstruksi atau fenomena yang menarik bagi banyak peneliti akan dibingkai secara berbeda tergantung pada perspektif yang diambil oleh peneliti tertentu (Jinfa Cai \& Stephen Hwang, 2019).

Menurut Suryanto (Muhfida, 2011) mengemukakan bahwa problem posing merupakan istilah dalam bahasa Inggris, sebagai padanan katanya digunakan istilah "merumuskan masalah (soal)" atau "membuat masalah (soal)". Problem posing mengacu pada generasi masalah baru berdasarkan situasi dan reformulasi masalah yang diberikan (Silver, 1994). Pentingnya problem posing dalam matematika sekolah telah diakui secara luas (Cai, Jiang, Hwang, Nie, \& Hu, 2016; Singer, Ellerton, \& Cai, 2015). Problem posing tidak hanya digunakan untuk menilai pemikiran siswa, tetapi juga sebagai strategi pembelajaran yang efektif untuk menciptakan lebih banyak kesempatan belajar bagi semua siswa (Cai \& Hwang, 2019). Dalam dua dekade terakhir, banyak kemajuan telah dibuat dalam penelitian problem posing (Cai et al., 2015). Para peneliti telah menemukan bahwa siswa dan guru mampu mengajukan masalah matematika berdasarkan situasi tertentu.

Proses belajar mengajar dengan pendekatan problem posing adalah sebagai berikut: Tahap Perencanaan, terdiri dari: 1) Penyusunan recana kegiatan dan bahan pembelajaran. 2) Guru mengorganisasi bahan pembelajaran dan mempersiapkannya. 3) Guru menyusun rencana pembelajaran. Tindakan. Terdiri dari: 1) Guru menjelaskan materi pelajaran kepada siswa. 2) Guru melakukan tes awal yang hasilnya digunakan untuk mengetahui tingkat daya kritis siswa. 3) Guru membentuk kelompok-kelompok belajar yang heterogen, setiap kelompok terdiri atas 5-6 orang. 4) Guru menugaskan setiap kelompok belajar untuk meresume beberapa buku yang berbeda. 5) Guru menugaskan masing-masing siswa dalam kelompok membuat pertanyaan dalam Lembar Kerja Peserta Didik (LKPD) I. 6) Kesemua tugas membuat pertanyaan dikumpulkan dalam kelompoknya kemudian dilimpahkan pada kelompok yang lainnya. 7) Setiap siswa dalam kelompoknya melakukan diskusi internal untuk menjawab pertanyaan yang diterima dari kelompok lain,setiap jawaban ditulis dalam lembar Lembar Kerja Peserta Didik II. 8) Pertanyaan yang telah ditulis dalam lembar problem posing I dikembalikan pada kelompok asal untuk kemudian di serahkan kepada guru dan jawaban pada lembar problem posing II diserahkan kepada guru. 9) Perwakilan dari setiap kelompok mempersentasikan hasil resume dan pertanyaan yang telah dibuatnya pada kelompok lain. 10) Guru menyuruh siswa kembali ketempat duduknya masing-masing. 11) Guru memberikan tugas rumah secara (Suryosubroto, 2009: 212). 
Salah satu model pembelajaran yang mendukung Kurikulum 2013 adalah model discovery learning. Menurut Bruner discovery learning adalah salah satu model instruksional kognitif yang menekankan pentingnya pemahaman tentang apa yang dipelajari dan memerlukan keaktifan dalam belajar sebagai dasar adanya pemahaman yang benar serta mementingkan proses berpikir induktif (Nurdyansyah dan Fahyuni, 2016). Discovery learning dianggap mampu memecahkan berbagai masalah dikarenakan oleh kelebihan dan efektivitas model pembelajaran tersebut (Windiyani dkk, 2020). Menurut Tumurun (2016) kelebihan discovery learning adalah: 1) melatih dan mengembangkan kemampuan berpikir kritis siswa, 2) kebermaknaan dalam kegiatan pembelajaran, dan 3) menjadikan siswa lebih bersemangat dalam belajar.

Discovery ialah proses mental dimana siswa mampu mengasimilasikan suatu konsep atau prinsip. Proses mental yang dimaksud antara lain: mengamati, mencerna, mengerti, menggolonggolongkan, membuat dugaan, menjelaskan, mengukur, membuat kesimpulan dan sebagainya. Dengan teknik ini siswa dibiarkan menemukan sendiri atau mengalami proses mental sendiri, guru hanya membimbing dan memberikan intruksi. Dengan demikian pembelajaran discovery ialah suatu pembelajaran yang melibatkan siswa dalam proses kegiatan mental melalui tukar pendapat, dengan berdiskusi, membaca sendiri dan mencoba sendiri, agar anak dapat belajar sendiri (Tumurun Septian Wahyu, 2016). Discovery learning merupakan salah satu model instruksional kognitif dari Jerome runner yang sangat berpengaruh. Menurut Brunner, discovery learning sesuai dengan pencarian pengetahuan secara aktif oleh manusia dan dengan sendirinya memberikan hasil yang baik. Berusaha sendiri untuk mencari pemecahan masalah serta pengetahuan yang menyertainya akan menghasilkan pengetahuan yang bermakna (Trianto, 2007).

\section{METODE}

Penelitian ini merupakan penelitian kuantitatif dengan menggunakan metode eksperimen. Populasi Penelitian adalah seluruh SMA Negeri 1 Kutalimbaru Tahun Ajaran 2020/2021. Teknik pengambilan sampel yang digunakan adalah teknik pengambilan sampel kelompok secara acak (cluster random sampling) yakni semua individu dalam kelas sampel menjadi subjek penelitian (Notoatmodjo, 2010). Pertimbangan pembuatan desain penelitian ini mengacu pada kelompok sampel yang digunakan sudah terbentuk sebelumnya, artinya peneliti tidak mengelompokkan sampel ke dalam kelompok-kelompok secara acak karena dapat menimbulkan gangguan terhadap efektivitas pembelajaran, sehingga desain penelitian yang digunakan adalah "non equivalent control-group design", yaitu kelompok PP dan kelompok DL diseleksi tanpa prosedur random, melainkan acak kelas, kemudian kedua kelompok sama-sama diberikan pre-test dan post-test (Creswell, 2010). Desain penelitian tersebut diilustrasikan sebagai berikut:

Kelompok Problem Posing
$\mathrm{O}$
$\mathrm{X}_{1}$

$\mathrm{O}$ 
$\begin{array}{llll}\text { Kelompok Discovery Learning } & \mathrm{O} & \mathrm{X}_{2} & \mathrm{O}\end{array}$

Dengan

$\mathrm{O} \quad$ : Pre-test/Post-test kemampuan berpikir kritis matematis

$\mathrm{X}_{1}$ : Model pembelajaran Problem Posing

$\mathrm{X}_{2} \quad$ : Pembelajaran Discovery Learning

Untuk mengumpulkan data penelitian maka dibuat teknik observasi dan tes. Observasi merupakan salah satu metode pengumpulan data dengan cara mengamati atau meninjau secara cermat dan langsung di lokasi penelitian untuk mengetahui kondisi yang terjadi atau membuktikan kebenaran dari sebuah desain penelitian yang sedang dilakukan. observasi merupakan "pengamatan dan pencatatan secara sistematis terhadap unsur-unsur yang nampak dalam suatu gejala pada objek penelitian" (Widoyoko, 2014). Aktivitas tersebut didasarkan pada pengetahuan dan gagasan yang bertujuan untuk mendapatkan informasi dari fenomena yang diteliti. Berikut ini adalah format lembar observasi aktivitas aktif guru dan siswa dalam pencapaian model problem posing dan discovery learning.

Tabel 1. Lembar observasi aktivitas aktif guru dan siswa dalam pencapaian model problem posing dan discovery learning

\begin{tabular}{|c|c|c|c|c|c|c|c|c|c|c|c|}
\hline \multirow{3}{*}{ No } & \multirow{3}{*}{ Indikator } & \multicolumn{10}{|c|}{ Pencapaian untuk Model } \\
\hline & & \multicolumn{5}{|c|}{ Problem Posing } & \multicolumn{5}{|c|}{ Discovery Learning } \\
\hline & & 1 & 2 & 3 & 4 & 5 & 1 & 2 & 3 & 4 & 5 \\
\hline 1 & $\begin{array}{l}\text { Kesiapan guru dalam mempersiapkan } \\
\text { materi sesuai dengan model }\end{array}$ & & & & & & & & & & \\
\hline 2 & $\begin{array}{l}\text { Aktivitas siswa selama siswa mengikuti } \\
\text { pembelajaran menggunakan model }\end{array}$ & & & & & & & & & & \\
\hline 3 & $\begin{array}{l}\text { Aktivitas guru selama melaksanakan } \\
\text { pembelajaran }\end{array}$ & & & & & & & & & & \\
\hline 4 & $\begin{array}{l}\text { Kemampuan siswa membuat keputusan } \\
\text { setelah pembelajaran } \\
\text { menggunakan model }\end{array}$ & & & & & & & & & & \\
\hline 5 & $\begin{array}{l}\text { Respon siswa selama mengikuti } \\
\text { pembelajaran }\end{array}$ & & & & & & & & & & \\
\hline
\end{tabular}

Lembar observasi diberikan kepada tiga orang observer untuk mengobservasi model problem posing dan tiga orang observer untuk mengobservasi model discovery learning. Data hasil pengamatan dianalis dengan mencari rata-rata skor kemampuan guru mengelola pembelajaran yang terdiri dari 5 kriteria; tidak baik (nilai 1), kurang baik (nilai 2), cukup baik (nilai 3), baik (nilai 4), sangat baik (nilai 5). Data akan disajikan dalam interval, maka kriteria tingkat kemampuan guru mengelola pembelajaran adalah:

$$
\begin{aligned}
& 1 \leq \mathrm{RHO}<2 \quad \text { (Tidak Baik) } \\
& 2 \leq \mathrm{RHO}<3 \text { (Kurang Baik) } \\
& 3 \leq \text { RHO }<4 \text { (Cukup Baik) }
\end{aligned}
$$




$$
\begin{aligned}
& 4 \leq \mathrm{RHO}<4,7 \text { (Baik) } \\
& 4,7 \leq \mathrm{RHO} \leq 5 \text { (Sangat Baik) }
\end{aligned}
$$

Keterangan $:$ RHO = Rerata Hasil Observasi (Situmorang Adi S., 2018)

Tes yaitu serentetan pertanyaan atau latihan serta alat lain yang digunakan untuk mengukur keterampilan, pengetahuan inteligensi, kemampuan atau bakat yang dimiliki oleh individu atau kelompok. Tes kemampuan berpikir kritismatematis yang digunakan dalam penelitian ini ada dua, yaitu pretes dan postes kemampuan berpikir kritismasing-masing sebanyak empat butir soal berbentuk uraian. Materi soal dan kisi-kisinya disesuaikan dengan silabus mata pelajaran matematika di kelas XII SMA dalam Kurikulum 2013 dan indikator kemampuan berpikir kritis. Tes ini digunakan sebelum pembelajaran (pretes) dan setelah pembelajaran (postes) dengan kedua model pembelajaran yaitu PP dan DL.

Data dalam penelitian ini bersifat data kuantitatif. Data tersebut diperoleh melalui TKPM, TBKM, dan skala SDT yang dilakukan sebelum (pretes) dan sesudah (postes) kegiatan pembelajaran. Data kuantitatif dianalisis secara statistik. Selanjutnya data kuantitatif dianalisis secara statistik menggunakan SPSS versi 23 yang ditujukan untuk menguji hipotesis-hipotesis yang diajukan.

\section{HASIL DAN PEMBAHASAN}

Sebagaimana dijelaskan pada metode penelitian bahwa teknik pengumpulan data pada penelitian ini adalah berupa teknik observasi dan tes, maka berikut ini akan dipaparkan dengan jelas hasil penelitian yang diperoleh.

1. Lembar observasi pencapaian pembelajaran

Saat pelaksanaan penelitian, tiga orang observer untuk masing masing kelas eksperimen melakukan observasi terkait tentang pencapaian aktivitas guru dan siswa sesuai dengan model pembelajaran discovery learning dan model pembelajaran problem posing. Berikut ini adalah hasil yang diperoleh.

Tabel 2. Hasil observasi aktivitas aktif guru dan siswa dalam pencapaian model problem posing dan

\begin{tabular}{|c|c|c|c|c|c|c|c|c|c|}
\hline \multirow{3}{*}{ No } & \multirow{3}{*}{$\begin{array}{l}\text { Indikator } \\
\text { Observasi }\end{array}$} & \multirow{2}{*}{\multicolumn{3}{|c|}{$\begin{array}{c}\text { Hasil Observasi Model } \\
\text { Problem Posing } \\
\text { Observer }\end{array}$}} & \multirow{3}{*}{ Rerata } & \multirow{2}{*}{\multicolumn{3}{|c|}{$\begin{array}{c}\begin{array}{c}\text { Hasil Observasi Model } \\
\text { Discovery Learning }\end{array} \\
\text { Observer }\end{array}$}} & \multirow{3}{*}{ Rerata } \\
\hline & & & & & & & & & \\
\hline & & 1 & 2 & 3 & & 1 & 2 & 3 & \\
\hline 1 & Indikator 1 & 5 & 5 & 5 & 5 & 5 & 5 & 5 & 5 \\
\hline 2 & Indikator 2 & 5 & 4 & 4 & 4,33333 & 5 & 4 & 5 & 4,66667 \\
\hline 3 & Indikator 3 & 5 & 5 & 5 & 5 & 5 & 5 & 5 & 5 \\
\hline 4 & Indikator 4 & 4 & 5 & 5 & 4,66667 & 5 & 5 & 4 & 4,66667 \\
\hline 5 & Indikator 5 & 5 & 5 & 5 & 5 & 5 & 5 & 5 & 5 \\
\hline & Total Rerata & & & & 4,8 & & & & 4,867 \\
\hline
\end{tabular}
discovery learning 
Dari tabel obsevasi aktivitas aktivitas aktif guru dan siswa dalam pencapaian model problem posing dan discovery learning di atas terlihat bahwa rerata pencapaian aktivitas aktif siswa dan guru sesuai dengan model pembelajaran problem posing adalah sebesar 4,8 dengan kategori "Sangat Baik". Sedangkan untuk pencapaian aktivitas aktif siswa dan guru sesuai dengan model pembelajaran discovery learning adalah sebesar 4,867 dengan kategori "Sangat Baik".

2. Analisis perbedaan model Problem Posing dan Discovery Learning terhadap Berpikir Kritis Siswa

Hasil penelitian yang berkenan dengan kemampuan berpikir kritis siswa diperoleh melalui tes berpikir kritis matematis. Hasil pretes dan postes tes berpikir kritis matematis digunakan sebagai data untuk mengetahui peningkatan kemampuan berpikir kritis. Soal tes tersebut terdiri atas 6 butir soal berbentuk uraian dengan materi statistika. Nilai rata-rata pada gain merupakan gambaran peningkatan kemampuan berpikir kritis siswa pada masing-masing pembelajaran, yaitu pembelajaran problem posing dan pembelajaran discovery learning. Guna memperoleh gambaran yang lebih rinci mengenai data peningkatan kemampuan berpikir kritis siswa, tabel 4.2 merangkum deskripsi data pretes, postes, dan peningkatan kemampuan berpikir kritis siswa berdasarkan pembelajaran.

Tabel 4.2

Deskripsi Data Berpikir Kritis Berdasarkan Pembelajaran

\begin{tabular}{|c|c|c|c|c|c|c|}
\hline \multirow{2}{*}{ Statistik } & \multicolumn{3}{|c|}{ Problem Posing } & \multicolumn{3}{c|}{ Discovery Learning } \\
\cline { 2 - 7 } & Pretes & Postes & $N$-Gain & Pretes & Postes & $N$-Gain \\
\hline maks & 30 & 68 & 0,79 & 33 & 79 & 0,98 \\
\hline $\min$ & 20 & 51 & 0,47 & 15 & 51 & 0,42 \\
\hline $\bar{x}$ & 25,15 & 62,05 & 0,67 & 25,90 & 65,05 & 0,72 \\
\hline$s$ & 2,74 & 5,15 & 0,10 & 4,76 & 5,07 & 0,10 \\
\hline \multicolumn{6}{|c|}{ Skor Maksimal Ideal: 80} \\
\hline
\end{tabular}

Tabel 4.2 memberikan informasi bahwa secara keseluruhan, rerata peningkatan kemampuan berpikir kritis siswa yang mengikuti pembelajaran problem posing hampir sama dengan siswa yang mengikuti pembelajaran discovery learning dengan selisih nilai hanya 0,05 . Bila dilihat dari sebaran data peningkatan kemampuan berpikir kritis siswa pada masing-masing kelompok pembelajaran, nilainya menunjukkan sebaran yang sama, yakni berada pada rentang 0,10. Dari tabel 4.2 juga diperoleh informasi rerata skor pretes kemampuan berpikir kritis siswa yang mengikuti pembelajaran problem posing lebih rendah daripada siswa yang mengikuti pembelajaran discovery learning (selisih rerata pretes sebesar 0,75$)$ dengan sebaran yang lebih beragam. Sebaran yang lebih beragam dapat dilihat dari nilai simpangan baku yang lebih besar pada kedua kelompok pembelajaran tersebut. Hal ini menunjukkan bahwa kedua kelas berada dalam kategori kemampuan berpikir kritismatematis yang sama.

Output hasil uji normalitas menggunakan SPSS versi 23, dan diperoleh nilai probabilitas (sig.) data kemampuan berpikir kritis matematisseluruh siswayangmemperoleh model problem posing dengan siswa yang memperoleh model discovery learningmasing-masing sebesar 0,39 dan 0,32. 
Kedua nilai signifikansi tersebut lebih tinggi dari taraf signifikansi 0,05 , sehingga $\mathrm{H}_{0}$ diterima. Ini berartibahwadatakemampuan berpikir kritis matematis masing-masingkelompokpembelajaran berdistribusi normal. Hasil uji homogenitas varians data kemampuan berpikir kritis matematissiswa kedua kelompok pembelajaran dengan menggunakan Uji Levene. Dari hasil analisis diperoleh nilai probabilitas (sig.) lebih kecil dari taraf signifikansi $\alpha=0,05$, sehingga $\mathrm{H}_{0}$ ditolak dengan kata lain variansi sampel dari data kemampuan berpikir kritis matematis adalah tidak homogen.

Selanjutnya untuk mengetahui apakah terdapat perbedaan kemampuan berpikir kritis matematis antara siswa yang memperoleh model problem posing dengan discovery learning menggunakan uji-t. Rangkuman hasil uji perbedaan rata-rata tersebut dapat dilihat pada tabel 4.12 berikut.

Tabel 4.12

Uji Perbedaan Rata-Rata Data Kemampuan Berpikir Kritis Matematis

\begin{tabular}{|c|c|c|c|c|}
\hline Pembelajaran & Perbedaan Rata-rata & $t^{\prime}$ & $\begin{array}{c}\text { Sig. } \\
(2 \text {-tailed })\end{array}$ & $\mathrm{H}_{0}$ \\
\hline Problem Posing & 25,15 & \multirow{2}{*}{$-0,611$} & 0,545 & Diterima \\
\hline Discovery Learning & 25,90 &
\end{tabular}

Dengan melihat ringkasan hasil analisis pada tabel 4.12 di atas, nilai $t$ probabilitas (sig.) untuk kedua pembelajaran lebih besar dari taraf signifikansi $\quad \alpha=0,05$ yang ditetapkan, sehingga $\mathrm{H}_{0}$ diterima. Dengan kata lain tidak terdapat perbedaan kemampuan berpikir kritis matematis antara siswa yang memperoleh model problem posing dengan siswa yang memperoleh model discovery learning. Hasil ini memberikan kesimpulan bahwa tidak terdapat perbedaan yang signifikan antara data kemampuan berpikir kritis matematis siswa yang memperoleh model problem posing dan dan siswa yang memperoleh model discovery learning.

\section{SIMPULAN}

Dari hasil dan pembahasan disimpulan bahwa walaupun rerata pencapaian untuk discovery learning lebih besar dari rerata pencapaian untuk problem posing namun tetap tidak terdapat perbedaan kemampuan berpikir kritis matematis antara siswa yang memperoleh model problem posing dengan discovery learning hal ini terjadi karena pencapaian proses pembelajara problem posing dan pencapaian proses pembelajaran discovery learning masih tetap sama-sama berada padakategori "Sangat Baik".

\section{DAFTAR RUJUKAN}

Bansal, P. 2011. Effectiveness of environment based experiential learning programme on critical thinking skills. Diviner: vol.8(2). 
Cai, J., Jiang, C., Hwang, S., Nie, B., \& Hu, D. (2016). How do textbooks incorporate mathematical problem posing? An international comparative study. In P. Felmer, E. Pehkonen, \& J. Kilpatrick (Eds.). Posing and solving mathematical problems: Advances and new perspectives (pp. 3-22).

Cai, J., \& Hwang, S. (2019). Learning to teach mathematics through problem posing: Theoretical considerations, methodology, and directions for future research. International Journal of Educational Research. https://doi.org/10.1016/j.ijer.2019.01.001 Online First.

Cai, J., Hwang, S., Jiang, C., \& Silber, S. (2015). Problem posing research in mathematics: Some answered and unanswered questions. In F. M. Singer, N. Ellerton, \& J.

Cai (Eds.). Mathematical problem posing: From research to effective practice. New York, NY: Springer.

Creswell, J.W. (2010). Research design: pendekatan kualitatif, kuantitatif, dan mixed. Yogjakarta: PT Pustaka Pelajar.

Enciso, O., Enciso, D., \& del Pilar Vargas Daza, M. (2017). Critical thinking and its importance in education: Some reflections. Rastros Rostros, 19(34), 78-88.

Esmaeili, Z., \& Bagheri, M. 2015. Evaluation of the Relationship between Critical Thinking Skills and affective Control in Child Training Students of the Female Technical and Vocational College in the City of Broujerd. IISTE- Journal of Education and Practice: 6(16) (28-36) https://files.eric.ed.gov/fulltext/EJ1079934.pdf

Muhfida. 2011. Pengertian Pendekatan Problemposing. Terdapat di http://muhfida.com/pengertianpendekatan-problem-posing/

Notoatmodjo, S. 2010. Metodologi Penelitian Kesehatan. Jakarta : Rineka Cipta.

Nurdyansyah dan Fahyuni,Eni Fariyarul.2016.Inovasi Model Pembelajaran Sesuai Kurikulum 2013. Sidoarjo: Nizamia Learning Center.

Olalekan, O. (2017). Critical thinking in Nigeria's pre-service teachers education: A philosophical investigation. Journal of Teacher Education and Educators, 6(2), 205-221.

Panggabean, E. M. (2015). Pengembangan Bahan Ajar Dengan Strategi React Pada Mata Kuliah Struktur Aljabar I Di FKIP UMSU. EduTech: Jurnal Ilmu Pendidikan dan IlmuSosial, 1(01).

Septian, Wahyu Tumurun. 2016. Model Pembelajaran Discovery Learning, Jurnal Pena Ilmiah: Vol. 1, No. 1 Maret-Agustus 2016.

Siahaan, Friska B. 2015. Pendekatan pembelajaran metakognitif Dengan Menekankan aspek analogi Untuk Meningkatkan Kemampuan Berpikirkritis Pada Mata Kuliah Kapita Selekta Matematika Di Prodimatematika FKIP Universitas HKBP Nommensen Medan. JSP-FKIP-UHN:2(2) (190200)

Sianipar, Linda. 2015. Model pembelajaran Team Games Tournament meningkatkan Hasilbelajarmahasiswa Prodi Ekonomi FKIP-UHN T.A2013/2014. JSP-FKIP-UHN:2(2) (143- 
Silver, E. A. (1994). On mathematical problem posing. For the Learning of Mathematics, 14(1), 1928.

Situmorang Adi S. 2018. Efektivitas Model Pembelajaran Contextual Teaching Andlearning Terhadap Kemampuan Pemahaman Konsep Matematismahasiswa Prodi Pendidikan Matematika FKIP UHN. URNAL Suluh Pendidikan FKIP-UHN: 5(1) (33-45)

Situmorang, Adi S. 2019. Perbedaan Pendekatan Pembelajaran Berbasis Masalah Berbantuan Software Dengan Pendekatan Open Ended Berbantuan Software Terhadap Kemampuan Pemecahan Masalah Matematis. SEPREN-UHN: 1(1).

Suryosubroto, A. 2009. Proses Belajar Mengajar di Sekolah. Jakarta.Rineka Cipta.

Trianto, Model-model Pembelajaran Inovatif Berorientasi Konstruktifistik, (Surabaya: Prestasi Pustaka Publisher, 2007), hlm. 26

Tumurun, Septiani Wahyu, Diah Gusrayanidan Asep Kurnia Jayadinata. (2016). Pengaruh Model Pembelajaran Discovery Learning Terhadap Keterampilan Berpikir Kreatif Siswa Pada Materi Sifat-Sifat Cahaya. Jurnal Pena Ilmiah, 1(1), 101-110. http://ejournal.upi.edu.

Ugwuozor, Felix Okechukwu, 2021. Determinants of critical thinking of trainee teachers: A production function approach. ELSEVIER: Volume 39, March 2021, 100765. https://doi.org/10.1016/j.tsc.2020.100765

Windiyani Tustiyana, Novita Lina, Sakinah Ananda Rizkiana. 2020. Pengaruh Penerapan Model Discovery Learningterhadap Hasil Belajar Matematika Siswa. Widyagogik, Vol. 7. No. 2. file:///C:/Users/HP/AppData/Local/Temp/7441-20395-1-PB.pdf

Widoyoko, Eko Putro. (2014). Teknik Penyusunan Instrumen Penelitian.Yogyakarta : Pustaka Pelajar 